\title{
Highlights on the Selective CDK4/6 Inhibitors
}

\author{
Jonas Cicenas*1-4 \\ ${ }^{1}$ Proteomics Centre, Institute of Biochemistry, Lithuania \\ ${ }^{2}$ MAP Kinase Resource, Bioinformatics, Switzerland \\ ${ }^{3}$ Energy and Biotechnology Engineering Institute, Lithuania \\ ${ }^{4}$ Vilnius Antakalnis Progymnasium, Lithuania \\ *Corresponding author: Jonas Cicenas , Proteomics Centre, Institute of Biochemistry, MAP Kinase Resource, Bioinformatics, Energy \\ and Biotechnology Engineering Institute, Vilnius Antakalnis Progymnasium, Lithuania
}

\section{ARTICLE INFO}

Received: 慧 January 30, 2019

Published: 幽 February 07, 2019

Citation: Jonas Cicenas. Highlights on the Selective CDK4/6 Inhibitors. Biomed J Sci \& Tech Res 14(2)-2019. BJSTR. MS.ID.002516.

\section{ABSTRACT}

Cyclin-dependent kinases (CDKs) play a important role in the control of the cell cycle and proliferation. These kinases are frequently deregulated in different cancers and other diseases. The involvement of CDKs in cancers led to an intensive search for small-molecule CDK inhibitors. Early attempts to inhibit CDKs with nonselective CDK inhibitors led to little specificity and effectivity but evident toxicity, but the recent advance of selective CDK inhibitors allowed the first successful efforts to target these kinases for the therapies. Probably, the most successful inhibitors so far in this respect are specific CDK4/6 inhibitors, which are discussed here.

Abbreviations: CDK: Cyclin Dependent Kinase; DFS: Disease Free Survival; SCLC: Small Cell Lung Cancer; NSCLC: Non-Small Cell Lung Cancer

\section{Introduction}

Cyclin-dependent kinases (CDK) are protein kinases of CMGC group, which play an necessary role in the control of the cell cycle, proliferation and transcription. In total there are 21 CDK genes in human genome and 11 of them are called "classical" CDKs. The "classical" ones are responsible for the activation of the cell cycle of quiescent cells and G1/M and G2/S transitions. Various CDKs are involved in different checkpoints of the cells cycle. For example, CDK 4 and 6 initiate the transition from quiescence to proliferation; CDK2 coordinates cell progression from G1 through S-phase, while CDK1 is a universal M-phase promoting factor. Diffrent CDKs also associate with various cyclins: CDK4/6 with cyclin D, CDK2 first with cyclin $\mathrm{E}$ and then with cyclin A and CDK1 with cyclin B [1,2]. Increased levels of expression and/or activity (especially CDK4, CDK6 and CDK2) have been observed in many different cancers [3-5]. Therefore, the search for the inhibitors of CDKs has been one of the interests of both academic and industrial scientific communities. To date, more than 30 different CDK small molecule inhibitors have been developed: broad-range inhibitors (such as, olomoucine, roscovitine, kenpaullone, SNS-032, AT7519, AG-
024322, R547), specific inhibitors (such as fascaplysin, ryuvidine, purvalanol A, NU2058, BML-259, SU 9516, P-276-00) and third generation inhibitors (such as dinaciclib). So far, the most hope lies with CDK4/6 specific inhibitors, namely: fascaplysin, LY2835219 and PD-0332991.

\section{Most Recent Research on Selective CDK4/6 Inhibitors}

\section{Fascaplysin}

Subtance originally isolated from the sponge Fascaplysinopsis bergquist, is a kinase inhibitor selective for CDK4 $($ IC50 $=0.35 \mu \mathrm{M})$ and CDK6 (IC50 $=3.4 \mu \mathrm{M})$ and not selective for the other CDKs or other kinases. (IC50 500 $\mu \mathrm{M}$ ) [3,4] and (Figure 1). Couple interesting preclinical studies were performed last year, one of which was lung cancer. Inhibitor showed high activity against Small Cell Lung Cancer (SCLC) (IC50=0.89 $\mu \mathrm{M})$ and Non-Small Cell Lung Cancer (NSCLC) cell lines (IC50 $1.15 \mu \mathrm{M}$ ) [6]. The other study on glioblastoma C6 cell line showed that the concentrations as low as $0.005 \mu \mathrm{M}$ were effective using fascaplysin, and the derivatives (7-phenylfascaplysin, 3-chlorofascaplysin, 3-bromofascaplysin, and 
10-bromofascaplysin) were even more effective than unsubstituted fascaplysin [7].

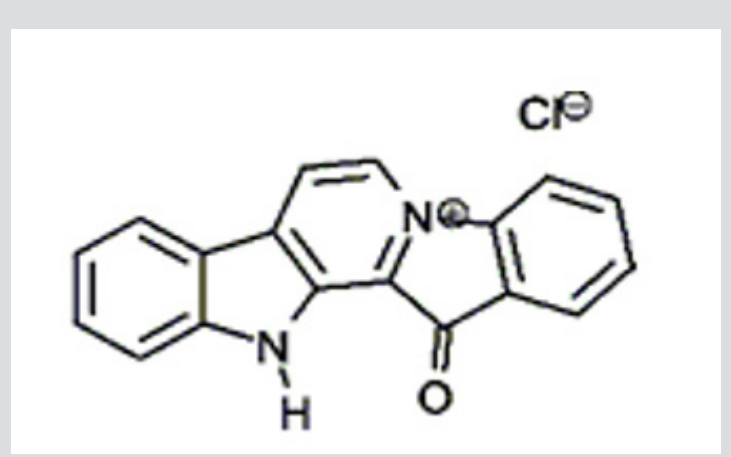

Figure 1: Fascaplysin.

\section{Abemaciclib (LY2835219)}

A potent and selective inhibitor of CDK4 (IC50=2 nM) and CDK6 ( IC50=10 nM). Earlier it was shown to be beneficial for patients with metastatic breast cancer [4]. In 2018, several interesting studies were performed using this inhibitor. The in preclinical xenograft mouse of Ewing sarcoma, it was shown that abemaciclib induced quiescence in cell lines via a G1 cell-cycle block. Decreased proliferation as well as reduction of Ki-67, FOXM1 expression and RB phosphorylation was also observed [8]. Combination study in patients with stage 4 NSCLC, showed an acceptable safety profile w in combination with pemetrexed, gemcitabine, or ramucirumab [9]. The clinical study in hormone receptor-positive advanced breast cancer in a special sub-group, called MONARCH 2 and MONARCH 3 , showed not only a, efficacy of abemaciclib as a combinatorial therapy, but also the prognostic factors for the diagnostics [10]. Palbociclib (PD-0332991): a highly specific inhibitor of CDK4 (IC50 $=0.011 \mu \mathrm{M})$ and CDK6 $($ IC50 $=0.016 \mu \mathrm{M})$, having no activity against a panel of 36 additional protein kinases [3,4] and (Figure 2). This selective CDK4/6 inhibitor is the most studied of all and it showed the most potency of all in clinical trials already in 2012 [11]. The most studies in 2018-2019 were also connected to the clinics, namely Phase I and/or Phase II studies. The combination study of palbociclib, fulvestrant, trastuzumab, and pertuzumab showed a significant effect on the expression of Ki67 at second week of treatment $(p<0 \cdot 0001)$ and at time of surgery $(p=0 \cdot 013)$ [12]. The effect was observed in ER, ERBB2, and RB1 in ERBB2-positive and ER-positive breast cancer. The other study demonstrated that palbociclib in combination with letrozole was quite effective as first-line treatment for ER+/HER2- advanced breast cancer showing that DFS probability was $75.0 \%$ (90\% CI, 61.3\%-84.4\%) [13]. The study of palbociclib in combination with letrozole or fulvestrant ERBB2-negative breast cancer, called PALOMA 1, 2 and 3 , the initial phase II/III studies that led to the U.S. Food and Drug Administration (FDA) approval of palbociclib in metastatic breast cancer, will continued including african american women [14].

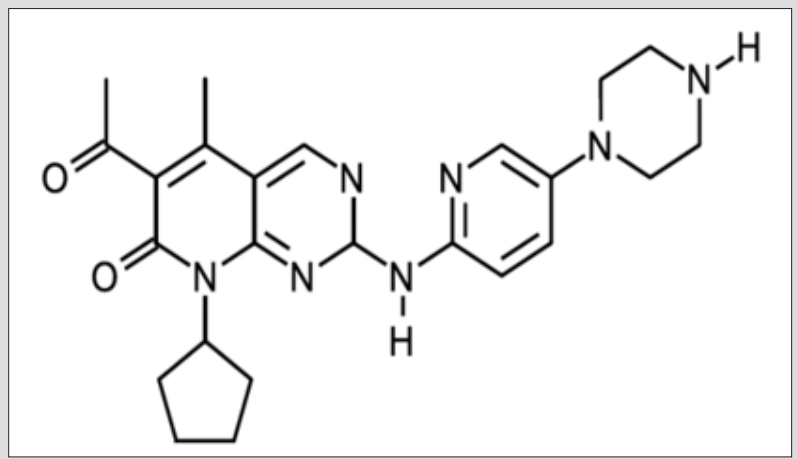

Figure 2: Palbociclib (PD-0332991).

The study of palbociclib as sigle agent in adult patients with recurrent RB1-positive glioblastoma demonstrated that palbociclib monotherapy was not an effective treatment, however since patients were heavily pretreated, different selection of treatment could still deserves to be explored [15]. Same story goes for the patients with metastatic urothelial cancer, where palbociclib did not demonstrate substantive activity in selected patients with platinum-refractory metastatic cancer [16]. PALLET trial with palbociclib together with letrozole in ER-positive breast cancer showed that palbociclib together with letrozole significantly enhanced the suppression of malignant cell proliferation (using Ki-67) in primary ER-positive cancer $(p<0.001)$ as well as complete cell-cycle arrest $(p<0.001)$ but did not increase the clinical response [17]. Phase I trial using the combination paclitaxel and palbociclib showed safety and clinical benefit in retinoblastoma protein-expressing, advanced breast cancer [18].

\section{Final Remarks}

The field of CDK4 / 6 inhibitor development had seen a significant during past several years. Nevertheless, there is still much room for improvement. Probably combination therapies with CDK4/6 inhibitors could be more promising than monotherapies, therefore more chemotherapeutic agents should be evaluated in combination. On the other hand other targeted drugs, such as inhibitors of other kinases might work together with CDK4/ inhibitors and should be evaluated. So far these inhibitors seem to be very promising and highly researched and used. There is overflowing promise!

\section{References}

1. Malumbres M, Barbacid M (2005) Mammalian cyclin-dependent kinases. Trends Biochem Sci 30(11): 630-641.

2. Malumbres M, Harlow E, Hunt T, Hunter T, Lahti JM, et al. (2009) Cyclindependent kinases: a family portrait. Nat Cell Biol 11(11): 1275-1276.

3. Cicenas J, Valius M (2011) The CDK inhibitors in cancer research and therapy. J Cancer Res Clin Oncol 137(10): 1409-1418.

4. Cicenas J, Kalyan K, Sorokinas A, Jatulyte A, Valiunas D, et al. (2014) Highlights of the latest advances in research on CDK inhibitors. Cancers (Basel) 6(4): 2224-2242.

5. Cicenas J, Kalyan K, Sorokinas A, Stankunas E, Levy J, et al. (2015) Roscovitine in cancer and other diseases. Ann Transl Med 3(10): 135. 
6. Rath B, Hochmair M, Plangger A, Hamilton G (2018) Anticancer Activity of Fascaplysin against Lung Cancer Cell and Small Cell Lung Cancer Circulating Tumor Cell Lines. Mar Drugs 16(10).

7. Lyakhova IA, Bryukhovetsky IS, Kudryavtsev IV, Khotimchenko YS, Zhidkov ME, et al. (2018) Antitumor Activity of Fascaplysin Derivatives on Glioblastoma Model In Vitro. Bull Exp Biol Med. 164(5): 666-672.

8. Dowless M, Lowery CD, Shackleford T, Renschler M, Stephens J, et al (2018) Abemaciclib Is Active in Preclinical Models of Ewing Sarcoma via Multipronged Regulation of Cell Cycle, DNA Methylation, and Interferon Pathway Signaling. Clin Cancer Res 24(23): 6028-6039.

9. Kim ES, Kelly K, Paz Ares LG, Garrido P, Jalal S, et al. (2018) Abemaciclib in Combination with Single-Agent Options in Patients with Stage IV NonSmall Cell Lung Cancer: A Phase Ib Study. Clin Cancer Res 24(22): 55435551.

10. Di Leo A, O Shaughnessy J, Sledge GW Jr, Martin M, Lin Y, F et al. (2018) Prognostic characteristics in hormone receptor-positive advanced breast cancer and characterization of abemaciclib efficacy. NPJ Breast Cancer $4: 41$.

11. Neil Bennet (2012) Oral CDK4/6 inhibitor in clinical trials. The Lancet Oncology 13(3).

12. Gianni L, Bisagni G, Colleoni M, Del Mastro L, Zamagni C, et al. (2018) Neoadjuvant treatment with trastuzumab and pertuzumab plus palbociclib and fulvestrant in HER2-positive, ER-positive breast cancer (NA-PHER2): an exploratory, open-label, phase 2 study. Lancet Oncol 19(2): 249-256.

ISSN: 2574-1241

DOI: 10.26717.BJSTR.2019.14.002516

Jonas Cicenas .Biomed J Sci \& Tech Res

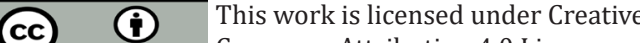
Commons Attribution 4.0 License

Submission Link: https://biomedres.us/submit-manuscript.php
13. Masuda N, Nishimura R, Takahashi M, Inoue K, Ohno S, et al. (2018) Palbociclib in combination with letrozole as first-line treatment for advanced breast cancer: A Japanese phase II study. Cancer Sci 109(3): 803-813.

14. Lynce F, Saleh M, Shajahan Haq A, Gallagher C, Dilawari A, et al. (2018) PALINA: A phase II safety study of palbociclib in combination with letrozole or fulvestrant in African American women with hormone receptor positive HER2 negative advanced breast cancer. Contemp Clin Trials Commun 10: 190-192.

15. Taylor JW, Parikh M, Phillips JJ, James CD, Molinaro AM, et al. (2018) Phase-2 trial of palbociclib in adult patients with recurrent RB1-positive glioblastoma. J Neurooncol 140(2): 477-483.

16. Rose TL, Chism DD, Alva AS, Deal AM, Maygarden SJ, et al. (2018) Phase II trial of palbociclib in patients with metastatic urothelial cancer after failure of first-line chemotherapy. Br J Cancer 119(7): 801-807.

17. Johnston S, Puhalla S, Wheatley D, Ring A, Barry P, et al. (2019) Randomized Phase II Study Evaluating Palbociclib in Addition to Letrozole as Neoadjuvant Therapy in Estrogen Receptor-Positive Early Breast Cancer: PALLET Trial. J Clin Oncol 37(3): 178-189.

18. Clark AS, Mc Andrew NP, Troxel A, Feldman M, Lal P, et al. (2019) Combination Paclitaxel and Palbociclib: Results of a Phase I Trial in Advanced Breast Cancer. Clin Cancer Res 790.

$\begin{array}{ll}\text { BIOMEDICAL } & \text { Assets of Publishing with us } \\ \text { RESEARCHES } & \text { - Global archiving of articles } \\ \text { - Immediate, unrestricted online access }\end{array}$

